Check for updates

Cite this: RSC Adv., 2017, 7, 19502

Received 28th February 2017

Accepted 24th March 2017

DOI: 10.1039/c7ra02458d

rsc.li/rsc-advances

\section{Retrieving aromaticity of dithiadiazuliporphyrin by oxidation: illustration by experimental and theoretical investigation $\uparrow$}

\author{
Young Mo Sung, ${ }^{a}$ Natasza Sprutta, ${ }^{\mathrm{b}}$ Jun Oh Kim, ${ }^{a}$ Yun Hee Koo, ${ }^{a}$ Lechostaw Latos- \\ Grażyński*b and Dongho Kim (DD*a
}

\begin{abstract}
The photophysical properties of neutral, monocation radical, and dication of dithiadiazuliporphyrin have been examined with a particular focus on their aromaticity. Dithiadiazuliporphyrin exhibits significantly different characteristics depending on its oxidation state. From these features, we could conclude that the aromaticity of dithiadiazuliporphyrin is changed from nonaromatic to aromatic upon oxidation from neutral to monocation radical and dication by $\mathrm{Br}_{2}$.
\end{abstract}

Over the last several decades, porphyrinoids and porphyrinrelated compounds have attracted considerable interest because of their fascinating properties, which can be used for diverse applications such as anion and cation sensing systems, nonlinear optical materials, magnetic materials, and near infrared (NIR) dyes. ${ }^{1}$ The stable aromatic and antiaromatic porphyrinoids have been easily prepared by a straightforward process, which can make them a good platform to realize versatile aromatic states including nonaromatic, Hückel aromatic and antiaromatic, and Möbius aromatic and antiaromatic states. ${ }^{1,2}$ Aromaticity is one of the most significant concepts in chemistry because it could determine the chemical and physical properties of molecules; aromatic species are more stable than nonaromatic compounds, while antiaromatic molecules are more unstable than nonaromatic compounds. ${ }^{3}$ In this regard, control of aromaticity in porphyrinoids has recently been in the limelight for chemists. To control aromaticity in porphyrinoids, various methods have been proposed including metalation, protonation, deprotonation, introduction of bridges, and the change in solvent polarity, temperature, and electronic state. ${ }^{4}$ Although there have been strenuous efforts to retrieve $\pi$-electron conjugation in porphyrinoids, only few studies have been conducted to find a direct effect of electronic oxidation in nonaromatic compounds.

Dithiadiazuliporphyrin ${ }^{5}$ synthesized by Sprutta et al. shows significantly different chemical properties from its dication species, which reflects closely their respective aromatic

${ }^{a}$ Department of Chemistry, Yonsei University, Seoul 120-749, Korea. E-mail: dongho@ yonsei.ac. kr; Fax: +82-2-2123-2434; Tel: +82-2-2123-2652

${ }^{b}$ Department of Chemistry, University of Wroctaw, 14 F. Joliot-Curie Street, 50-383, Wrockaw, Poland. E-mail: lechoslaw.latos-grazynski@chem.uni.wroc.pl; Fax: +48713-282-348; $\mathrm{Tel}$ : +48-71-3757256

$\dagger$ Electronic supplementary information (ESI) available. See DOI: $10.1039 / \mathrm{c} 7 \mathrm{ra02458d}$ properties (Chart 1). Although the basic chemical properties of dithiadiazuliporphyrin depending on its oxidation state were characterized in previous study, the detailed analysis for aromaticity such as photophysical properties and theoretical calculations has rarely been studied. In this regard, dithiadiazuliporphyrin could be the best candidate to unravel the change of aromaticity depending on its charged species, which provides a clue to control the aromaticity by oxidation. Accordingly, we have investigated the aromaticity of neutral, dication and in particular monocation radical, of dithiadiazuliporphyrin by using spectroscopic measurements and theoretical calculations. Moreover, the aromaticity of monocation radical is of a special interest as, because of electronic structure, it could not be addressed by standard NMR approach. ${ }^{5}$

The absorption spectrum of dithiadiazuliporphyrin exhibits two broad bands at 443 and $514 \mathrm{~nm}$ with smeared and weak tail in near infrared (NIR) region, which is close to the absorption spectra of typical nonaromatic porphyrinoids (Fig. 1). The absorption spectrum of dithiadiazuliporphyrin is changed twice upon addition of oxidant $\left(\mathrm{Br}_{2}\right)$. The oxidant shows weak absorption spectrum in $350-600 \mathrm{~nm}$, which could be negligible from the absorption spectra of dithiadiazuliporphyrins. ${ }^{6}$ First, adding three equivalents of $\mathrm{Br}_{2}$ to dithiadiazuliporphyrin

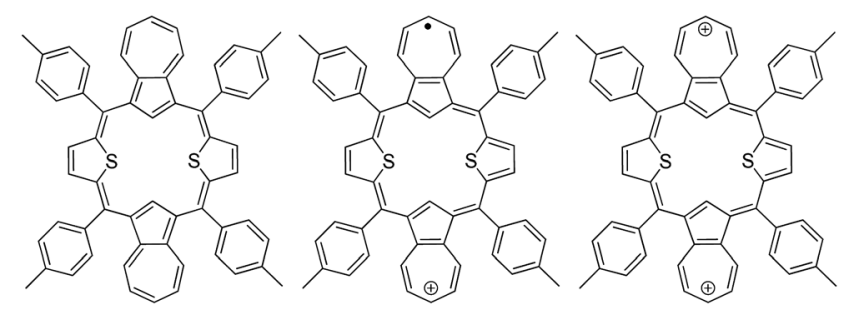

Chart 1 Molecular structures of dithiadiazuliporphyrins and its oxidized derivatives. 

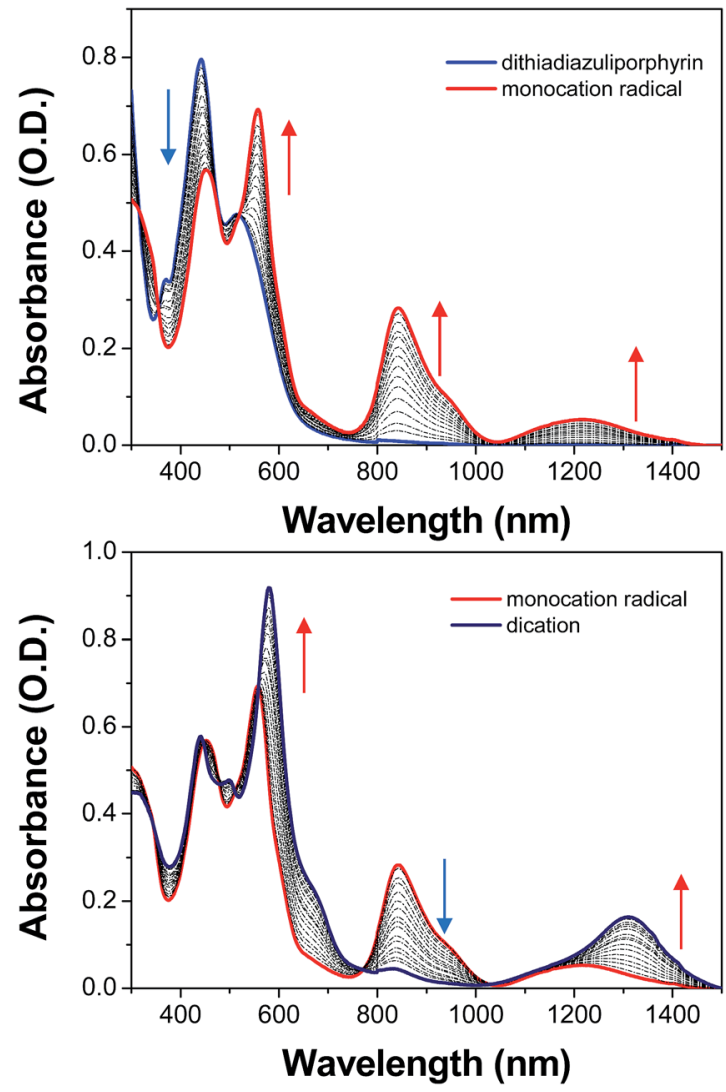

Fig. 1 The absorption spectral change of dithiadiazuliporphyrin upon adding $0-3$ equivalent (top) and $3-7.4$ equivalent (bottom) of $\mathrm{Br}_{2}$.

solution, distinct bands appear at longer than $800 \mathrm{~nm}$ region in the absorption spectra, assigned as monocation radical form. Furthermore, adding more 4.4 equivalents of $\mathrm{Br}_{2}$, the absorption spectra exhibit decreased band in 800-1000 $\mathrm{nm}$ region with red-shifted and intensified bands at 580 and $1311 \mathrm{~nm}$, indicative of formation of dication. The previous study ${ }^{5}$ revealed that the dication species of dithiadiazuliporphyrin exhibit up-field shift of inner protons in ${ }^{1} \mathrm{H}-\mathrm{NMR}$ spectra, which indicate the retrieved aromatic features in oxidized states. Contemplating that the dication species exhibit aromatic features in ${ }^{1} \mathrm{H}-\mathrm{NMR}$ and the absorption spectra of monocation radical and dication of dithiadiazuliporphyrins exhibit similar trends, those absorption spectra exhibiting relatively intense band in visible region and weak bands in NIR region could be easily rationalized by Gouterman's four orbital model. ${ }^{7}$ In other words, the absorption spectra of oxidized dithiadiazuliporphyrins resembles those of typical aromatic porphyrinoids. In this regard, we could assume that the oxidized forms of dithiadiazuliporphyrin are aromatic, while its neutral form is nonaromatic.

The characteristic aromatic features of oxidized dithiadiazuliporphyrins could also be observed in the excited state dynamics (Fig. 2). The femtosecond transient absorption (TA) spectra of neutral dithiadiazuliporphyrin show weak ground state bleaching with relatively strong excited state absorption. In addition, the decay profiles are fitted with double exponential function giving rise to two time constants of 0.6 and $27 \mathrm{ps}$. The
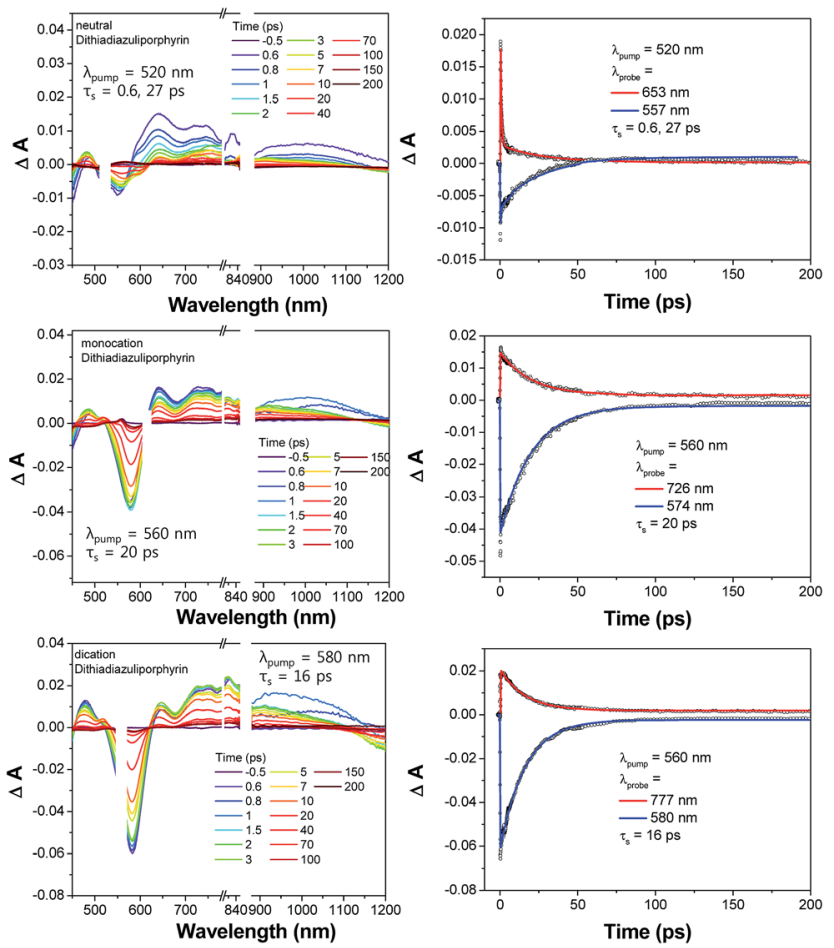

Fig. 2 TA spectra of neutral (top), monocation radical (middle), and dication (bottom) of dithiadiazuliporphyrins.

excited state dynamics of neutral form is common features of nonaromatic porphyrinoids. ${ }^{8}$ Taking the origin of excited state dynamics in nonaromatic porphyrinoids into consideration, the fast decay process within 1 ps would be the internal conversion from high energy states to the lowest excited state, which is induced by the optically dark state in the low energy region. The relatively slow decay component ( $27 \mathrm{ps)}$ could be assigned to the lowest singlet excited state lifetime. Contrary to this, the TA spectra of the oxidized species show strong ground state bleaching signal with relatively weak excited state absorption, which is the typical TA spectral features of aromatic porphyrinoids. ${ }^{8,9}$ Such macrocycles generally show weak excited state absorption with strong bleaching band due to the aromaticity reversal in the excited state.

Aromaticity in the ground state of expanded porphyrins would be reversed in the lowest triplet or singlet excited state. ${ }^{9}$ Moreover, the absorption spectra of expanded porphyrins

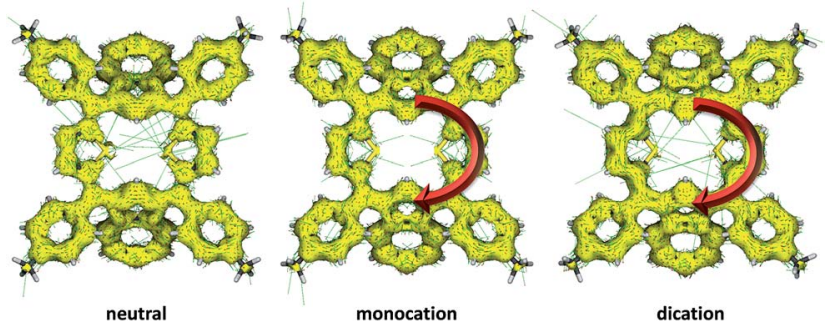

Fig. 3 ACID plots of neutral (left), monocation radical (middle), and dication (right) of dithiadiazuliporphyrins. 
exhibit aromaticity-dependent behavior; the absorption spectra of aromatic expanded porphyrins show intense B-like bands with distinct Q-like bands, while those of antiaromatic expanded porphyrins present weak and broad bands in visible region with dark state in NIR region. ${ }^{8}$ In this regard, the transient absorption spectra of aromatic expanded porphyrins show strong ground state bleaching spectra originated from ground state aromatic behavior with weak excited state absorption caused by antiaromatic character in the excited state.

In addition, the single exponential decay process is typical in aromatic porphyrinoids due to their small energy gaps among the energy states which can induce fast internal conversion processes less than 100 fs. These results also represent that the aromatic features of dithiadiazuliporphyrins are generated by oxidation using $\mathrm{Br}_{2}$.

To understand the detailed photophysical properties observed in dithiadiazuliporphyrin upon oxidation with $\mathrm{Br}_{2}$, the vertical energy transitions were calculated (see the ESI $\dagger$ ). In the case of neutral form, the lowest energy transition around $800 \mathrm{~nm}$ is a forbidden transition (HOMO-LUMO). Furthermore, the analysis of distribution of electron densities related to electron(s) placed on the frontier molecular orbitals (FMOs) reveals a preference for location on the selected sections but not on the entire ring, which is significantly different from aromatic porphyrinoids. These calculation results reflect the experimental features (broad absorption band with tail and double exponential decay process). ${ }^{\mathbf{8} 9}$ On the contrary to neutral species, oxidized forms (mono- and dication) show different features. In the TD-DFT calculations, we couldn't observe the forbidden transition of oxidized dithiadiazuliporphyrins in the lowest energy region. Moreover, the frontier MOs of oxidized dithiadiazuliporphyrins exhibit porphyrin-like MO structures having fully localized electron densities in the entire ring, although the energy levels are not degenerate in HOMOs and LUMOs due to the expansion of $\pi$-conjugation to fused tropylium moieties in azulene. These results also support the retrieved aromaticity of oxidized dithiadiazuliporphyrins which induces the porphyrinlike absorption and single exponential decay process.

To get more detailed introduction on the aromaticity change in dithiadiazuliporphyin upon oxidation with $\mathrm{Br}_{2}$, several aromaticity indices were calculated (see the ESI $\dagger$ ). The harmonic oscillator model of aromaticity (HOMA) values, ${ }^{\mathbf{1 0}}$ the representative topological aromaticity indices, of a series of dithiadiazuliporphyrins were estimated. The estimated HOMA values increase in going from neutral dithiadiazuliporphyrin (0.301) to monocation radical (0.556) and dication forms (0.698), which implies that the aromaticity is enhanced in charged species. Thus, it could be deduced that the aromaticity is retrieved and enhanced upon oxidation from neutral form to monocation radical and dication species of dithiadiazuliporphyrin.

Furthermore, the magnetic aromaticity indices are consistent with topological aromaticity indices. The nucleus independent chemical shift (NICS) ${ }^{11-13}$ which is well-known as an absolute magnetic aromaticity index. In case of dithiadiazuliporphyrin and its oxidized forms the appropriate NICS values were calculated at the center of macrocyclic ring (see the ESI $\dagger$ ).
Although it is hard to observe the evidence for the aromaticity of monocation radical in ${ }^{1} \mathrm{H}-\mathrm{NMR}$, NICS calculation provides clear features in aromaticity of radical species. The NICS(0) values of neutral, monocation radical, and dication of dithiadiazuliporphyrin were estimated to be $0.415,-2.881$, and -6.592 , respectively. More negative $\operatorname{NICS}(0)$ values in going from neutral to mono- and dication imply that the aromaticity of dithiadiazuliporphyrins changes from nonaromatic to aromatic, which are in line with the above experimental and theoretical results. In addition, the anisotropy of induced current density (ACID) plots,${ }^{14}$ which illustrate the degree of aromaticity by the current flows of molecules in external magnetic fields, given for dithiadiazuliporphyrin and its cation show a similar tendency as shown by the calculated NICS values (Fig. 3). In the case of neutral species, the current flows are disconnected in the macrocyclic ring and localized on the local rings (azulene and thiophene). In the case of mono- and di-cation of dithiadiazuliporphyrins, however, both of the ACID plots display clockwise ring current flows in the macrocyclic ring, although thicker current densities which indicate stronger aromatic features are observed in dication form compared to those of monocation radical. In other words, the aromaticity of dithiadiazuliporphyrin is retrieved in monocation and enhanced in dication. Thus, all the calculation results would illustrate the retrieval of aromaticity in dithiadiazuliporphyrin upon oxidation by $\mathrm{Br}_{2}$.

In summary, the photophysical properties and theoretical calculations of dithiadiazuliporphyrin, its monocation radical and dication have been investigated from a viewpoint of aromaticity. The changed absorption spectra and excited state dynamics in oxidized dithiadiazuliporphyrin accompanied by an alternation in theoretical aromaticity indices indicate the generation and enhancement of aromaticity in dithiadiazuliporphyrin resulting from oxidation. Furthermore, these results provide significant insight into rational redox control of an aromatic behavior.

\section{Acknowledgements}

The work at Yonsei University was supported by the Global Research Laboratory Program (GRL, 2013K1A1A2A0205183) funded by the Ministry of Science, ICT \& Future, Korea. The quantum calculations were performed using the supercomputing resources of the Korea Institute of Science and Technology Information (KISTI). The work at the University of Wrocław was supported by National Science Centre (Grant Number: 2012/04/A/ST5/00593).

\section{Notes and references}

1 (a) J. L. Sessler and D. Seidel, Angew. Chem., Int. Ed., 2003, 42, 5134; (b) M. Stępień, N. Sprutta and L. Latos-Grażyński, Angew. Chem., Int. Ed., 2011, 50, 4288; (c) S. Saito and A. Osuka, Angew. Chem., Int. Ed., 2011, 50, 4342.

2 (a) J.-Y. Shin, K. S. Kim, M.-C. Yoon, J. M. Lim, Z. S. Yoon, A. Osuka and D. Kim, Chem. Soc. Rev., 2010, 39, 2751; (b) S. Cho, Z. S. Yoon, K. S. Kim, M.-C. Yoon, D.-G. Cho, J. L. Sessler and D. Kim, J. Phys. Chem. Lett., 2010, 1, 895-900. 
3 (a) V. I. Minkin, M. N. Glukhovtsev and B. Y. Simkin, Aromaticity and Antiaromaticity: Electronic and Structural Aspects, John Wiley \& Sons, New York, 1994; (b) M. K. Cyrański, Chem. Rev., 2005, 105, 3773.

4 (a) M. Stepień, L. Latos-Grażyński, N. Sprutta, P. Chwalisz and L. Szterenberg, Angew. Chem., Int. Ed., 2007, 46, 7869; (b) J.-Y. Shin, L. J. Min, Z. S. Yoon, K. S. Kim, M.-C. Yoon, S. Hiroto, H. Shinokubo, H. Shimizu, A. Osuka and D. Kim, J. Phys. Chem. B, 2009, 113, 5794; (c) A. Jana, M. Ishida, K. Cho, S. K. Ghosh, K. Kwak, K. Ohkubo, Y. M. Sung, C. M. Davis, V. M. Lynch, D. Lee, S. Fukuzumi, D. Kim and J. L. Sessler, Chem. Commun., 2013, 49, 8937; (d) Y. M. Sung, M.-C. Yoon, J. M. Lim, H. Rath, K. Naoda, A. Osuka and D. Kim, Nat. Chem., 2015, 7, 418.

5 N. Sprutta, M. Świderska and L. Latos-Grażyński, J. Am. Chem. Soc., 2005, 127, 13108.

6 S. Hubinger and J. B. Nee, J. Photochem. Photobiol., A, 1995, 86, 1-7.

7 M. Gouterman, G. H. Wagniere and L. C. Snyder, J. Mol. Spectrosc., 1963, 11, 108.
8 M.-C. Yoon, S. Cho, M. Suzuki, A. Osuka and D. Kim, J. Am. Chem. Soc., 2009, 131, 7360.

9 (a) Y. M. Sung, J. Oh, W. Kim, H. Mori, A. Osuka and D. Kim, J. Am. Chem. Soc., 2015, 137, 11856; (b) J. Oh, Y. M. Sung, W. Kim, S. Mori, A. Osuka and D. Kim, Angew. Chem., Int. Ed., 2016, 55, 6487; (c) Y. M. Sung, J. Oh, K. Naoda, T. Lee, W. Kim, M. Lim, A. Osuka and D. Kim, Angew. Chem., Int. Ed., 2016, 55, 11930.

10 (a) T. M. Krygowski and M. K. Cyrański, Tetrahedron, 1999, 55, 11143; (b) T. M. Krygowski and M. K. Cyrański, Chem. Rev., 2001, 101, 1385.

11 P. v. R. Schleyer, C. Maerker, A. Dransfeld, H. Jiao and N. J. R. v. E. Hommes, J. Am. Chem. Soc., 1996, 118, 6317.

12 V. Gogonea, P. v. R. Schleyer and P. R. Schreiner, Angew. Chem., Int. Ed., 1998, 37, 1945.

13 S. Suzuki, Y. Morita, K. Fukui, K. Sato, D. Shiomi, T. Takui and K. Nakasuji, J. Am. Chem. Soc., 2006, 128, 2530.

14 D. Geuenich, K. Hess, F. Köhler and R. Herges, Chem. Rev., 2005, 105, 3758. 